\title{
ESCOLA SEM PARTIDO: UM PROGRAMA DE CONTROLE NA SALA DE AULA
}

\author{
ESCOLA SEM PARTIDO: A CONTROL PROGRAM IN THE \\ CLASSROOM
}

Gerson Vasconcelos Luz ${ }^{1}$

RESUMO: O artigo traz à baila a questão da doutrinação política e ideológica apresentada pelo Escola sem Partido. Segundo os defensores do programa, há professores doutrinadores no ambiente escolar e a prática precisa ser combatida. Porém, ao estudarmos o conteúdo do programa, replicado em diversos projetos de leis em inúmeras casas legislativas pelo Brasil, inferimos que o movimento tende a propor instrumentos que sirvam de controle no sentido de inibir a abordagem de assuntos adversos às ideologias do próprio programa. $\mathrm{O}$ alvo desse instrumento de controle são os professores e produtores de materiais didáticos.

PALAVRAS-CHAVE: Escola sem Partido; educação; ensino básico.

ABSTRACT: The article brings up the issue of political and ideological indoctrination presented by Escola sem Partido. According to supporters of the program, there are indoctrinating teachers in the school environment and the practice needs to be combated. However, when we study the content of the program, replicated in several bills of law in numerous legislative houses throughout Brazil, we infer that the movement tends to propose instruments that serve as controls in order to inhibit the approach of issues adverse to the ideologies of the program itself. The target of this control instrument is teachers and producers of teaching materials.

KEYWORDS: Escola sem Partido; education; basic education.

\footnotetext{
*Este artigo se origina de pesquisas realizadas entre 2016 e 2017 no curso de pós-graduação lato sensu em Educação e Sociedade pelo Instituto Federal do Paraná, campus Jacarezinho sob orientação do Prof. Dr. Rodolfo Fiorucci.

${ }^{1}$ Doutorando em Filosofia pela Universidade Estadual de Londrina (UEL), mestre em Filosofia pela Universidade Estadual do Oeste do Paraná (UNIOESTE), graduado em Filosofia pela Universidade Estadual do Oeste do Paraná (UNIOESTE), professor de educação básica pela Secretaria de Estado da Educação do Paraná (SEED-PR). Endereço eletrônico: gersonvasconcelos.luz@gmail.com
} 


\section{Introdução}

"A cadela do fascismo está sempre no cio" (Bertold Brecht).

O programa Escola sem Partido não é novo. Tampouco é nova a ideia de que muitos professores praticam proselitismo político e religioso no ambiente escolar. Mas, a partir de 2014 as discussões em torno do assunto se tornaram mais frequentes.

Em 2015 o Escola sem Partido chega no Congresso Nacional. Primeiro na Câmara dos Deputados com o Projeto de Lei ${ }^{\circ}$ 867, de 2015, de autoria de Izauci Lucas Ferreira (PSDB), sendo posteriormente apensado ao Projeto de Lei $\mathrm{n}^{\circ}$ 7.180, de 2014, de autoria de Erivelton Lima Santana (PSC) ${ }^{2}$. No projeto propõe-se que seja acrescido o inciso XIII ao Art. $3^{\circ}$ da Lei das Diretrizes e Bases da Educação Nacional. Com o referido inciso exige-se que seja respeitado as convicções "[...] do aluno, de seus pais ou responsáveis, tendo os valores de ordem familiar precedência sobre a educação escolar nos aspectos relacionados à educação moral, sexual e religiosa [...]"3. O segundo projeto de lei - similar ao anterior - foi registrado no Senado Federal no ano seguinte, com o ${ }^{\circ} 193$, de autoria de Magno Pereira Malta (PR) ${ }^{4}$.

Os dois projetos têm por objetivo incluir "entre as diretrizes e bases da educação nacional, de que trata a Lei n 9.394, de 1996, o 'Programa Escola sem Partido","

O programa propõe a "Neutralidade política, ideológica e religiosa do Estado", no âmbito da sala de aula. Entretanto, como se pode inferir a partir da citação que segue, a proposta é parcial, pois, faz referência à "[...] determinadas correntes políticas e ideológicas [...]"6 e não ao todo da questão. Essa ideia, reforçada por várias passagens ao longo do texto, abre margem para questionamentos, entre os quais elenquemos estes: se neutro é aquele que não

\footnotetext{
${ }^{2}$ Atualmente filiado ao PATRI.

${ }^{3}$ Projeto de Lei 7.180, 2014, Art. $3^{\circ}$, inciso XIII.

${ }^{4}$ A partir de 2019 o partido mudou a sigla para PL (Partido Liberal).

${ }^{5}$ Projeto de Lei 193, 2016, Art. $2^{\circ}$, inciso I.

${ }^{6}$ Projeto de Lei 193, 2016, justificação.
} 
toma posição nem contra nem a favor de um ou de um conjunto de ideias, o projeto não estaria propondo uma neutralidade especiosa? Uma vez transformada em lei, o "Escola sem Partido" não serviria de instrumento de controle sobre determinados conteúdos curriculares?

Defendemos a hipótese de que se o programa for aprovado no Congresso Nacional e sancionado pela Presidência da República, além de se constituir em mais um instrumento burocrático desnecessário, o Escola sem Partido poderia ser utilizado como mecanismo de controle no sentido de inibir a abordagem de temas desagradáveis à ideologia (ou ideologias) dos defensores do programa.

A pesquisa teve como objetivos analisar o Escola sem Partido; identificar determinadas correntes políticas e ideológicas as quais o proponente do programa faz menção; investigar a questão da neutralidade; e, em termos específicos, discutir suas possíveis consequências e implicações no âmbito escolar.

A metodologia empregada na pesquisa foi de caráter teórico e bibliográfico, consistindo em leituras, análises de textos e de discussões em torno do tema. Inicialmente, foi analisado o Escola sem Partido; posteriormente, os referidos projetos de leis registrados no Congresso Nacional, bem como outros projetos similares em discussão ou já aprovados em diversas casas legislativas pelo Brasil. Num terceiro momento, foram examinados materiais didáticos, paradidáticos e obras críticas sobre o tema. Com o intuito de compreender o debate entre os intelectuais brasileiros, recorreu-se ainda, à programas de TV, textos de jornais e revistas. Para melhor lidar com os dados e assuntos resultante da pesquisa, o artigo está dividido em três partes.

\section{Nascimento e ascensão do Escola sem Partido}

Na seção FAQ do website do Escola sem Partido, o programa é definido como "[...] um conjunto de medidas [...], que tem por objetivo inibir a prática da doutrinação política e ideológica em sala de aula e a usurpação do direito dos 
pais dos alunos sobre a educação moral dos filhos"”. O Escola sem Partido, criado em $2004^{8}$, começou a se tornar nacionalmente conhecido em 2014, quando o Deputado Flávio Bolsonaro $(\mathrm{PP})^{9}$ convidou o autor, o advogado Miguel Nagib para redigir a proposta que foi apresentada na Assembleia Legislativa do Estado do Rio de Janeiro como Projeto de Lei (MANHAS, 2016: 19). Logo depois, o vereador Carlos Bolsonaro (PP) ${ }^{10}$ apresentou um projeto similar na Câmara de vereadores do Município do Rio de Janeiro. Depois disso, o programa se espalhou pelo Brasil.

No Estado do Paraná, o Escola sem Partido chegou com o Projeto de Lei $\mathrm{n}^{\circ}$ 748, de 2015, assinado pelo deputado Gilson de Souza (PSC) e mais 11 parlamentares. O projeto foi arquivado $^{11}$ no mesmo ano. Em 2016 um projeto similar reaparece na Assembleia Legislativa do Estado do Paraná (Alep) com $\mathrm{n}^{\circ}$ 606, de autoria do Deputado Missionário Ricardo Arruda $(\mathrm{PEN})^{12}$. No interior do estado, em Santa Cruz de Monte Castelo o projeto com o mesmo conteúdo tramitou e foi aprovado na Câmara de Vereadores do município e implementado em 2016.

Em Alagoas, a "Lei da Escola Livre", de autoria do Deputado Ricardo Nezinho (PMDB) ${ }^{13}$, tornou-se a Lei Estadual $n^{\circ} 7.800$, de 2016. Mas foi vetada integralmente pelo governador do Estado. O veto foi derrubado e a Lei promulgada (05/05/2016). Logo em seguida, o Conselho Nacional dos Trabalhadores em Educação (CNTE) ajuizou no Supremo Tribunal Federal (STF) uma Ação Direta de Inconstitucionalidade (ADI). Por último, o Supremo decidiu em caráter liminar que a Lei é inconstitucional.

Há muitos outros registros do Escola sem Partido em diversas casas legislativas pelo Brasil. Mas, qual é a sua real necessidade? Qual é o

\footnotetext{
${ }^{7}$ Disponível em: <http://escolasempartido.org/faq/>. Acessado em 10/12/2016.

8 O movimento "foi precedido de toda uma tradição intelectual eminentemente liberal, conservadora e, fundamentalista religiosa" (KATZ; MUTZ, 2017: 186).

${ }^{9}$ Atualmente Senador pelo mesmo estado e sem filiação partidária (informações atualizadas em 21/01/2020).

${ }^{10}$ Atualmente filiado ao PSL.

${ }^{11}$ Em 03/12/2015, a pedido do autor.

12 Atualmente filiado ao PSL.

${ }^{13}$ Em convenção nacional extraordinária do partido transcorrida em 19/12/2017 aprovou-se a mudança da sigla para MDB.
} 
fundamento teórico do Programa? Qual é a literatura utilizada como base para discussão do tema?

$\mathrm{Na}$ etapa de levantamento bibliográfico para a realização da pesquisa que originou o presente artigo, notou-se que há pouca prova material e estudos significativos em torno da questão no sentido de sustentar as ideias postas no programa.

Defendemos que é necessário fundamentar a discussão em estudos, pesquisas e opiniões de uma vasta gama de estudiosos (brasileiros e estrangeiros). O website e a fanpage do movimento no Facebook não apresentam dados suficiente para comprovar que há ou não doutrinação política, ideológica e religiosa no ambiente escolar. O que consta são peças que apontam para situações pontuais. Não fica claro e evidente que há um problema em termos educacionais e que a única via de resolução seria a criação de uma lei.

Segundo Ratier (2016: 31), “a doutrinação em si é sempre errada. A questão é saber se esse é um problema amplamente disseminado pelo país ou se é uma questão pontual em algumas escolas". Ao que parece, trata-se de situações pontuais. Em face disso, não há razão para a generalização e criação de lei(s).

Se a doutrinação fosse um problema generalizado ter-se-ia que reunir provas consistentes, realizar pesquisas, ouvir as partes diretamente envolvidas na questão (pais, responsáveis, docentes e discentes). Depois disso, caso se constatasse a existência de doutrinação e que esta causa males que afetam a educação de nossos estudantes, se justificaria a existência de normas legais para proibir a tal prática.

Ratier (2016: 31) argumenta que "o projeto se baseia em relatos esparsos e em uma pesquisa de 2008 encomendada pela revista Veja ao Instituto CNT/Sensus"14, que ao publicar os resultados traz uma reportagem

\footnotetext{
${ }^{14}$ A pesquisa ouviu 3.000 pessoas em 24 estados brasileiros (pais, alunos e professores de escolas públicas e privadas). A reportagem de Veja não traz detalhes sobre a metodologia utilizada na pesquisa.
} 
apontando que há "[...] uma tendência prevalente entre os professores brasileiros de esquerdizar a cabeça das crianças" (Veja, 2008: 77).

Na publicação afirma-se ainda, os alunos da educação básica

[...] estão sendo preparados para viver no final do século XIX, quando o marxismo surgiu como ideologia modernizante, capaz não apenas de explicar, mas de mudar o mundo para melhor, acelerando a marcha rumo a sociedade sem classe (Veja, 2008: 77).

Nota-se que o tom sarcástico da escrita ao se referir ao marxismo se assemelha aos discursos encontrados nas postagens contidas no website e na fanpage do Facebook do Programa.

Em outra passagem da reportagem, se pode ler:

Muitos professores brasileiros se encantam com personagens que em classe mereceriam um tratamento mais criterioso [...]. Idolatram personagens arcanos sem contribuição efetiva à civilização ocidental, como o educador Paulo Freire, autor de um método de doutrinação esquerdista disfarçado de alfabetizador (Veja, 2008: 82).

A análise da reportagem de Veja, bem como a transcrição de passagens de comentário à referida pesquisa, que embasa o programa, nos instiga a indagar: que tipo de doutrinação política e ideológica se quer neutralizar? A leitura de leis e de projetos em andamento, aprovados e arquivados sobre o programa oferecem pistas para a resposta. Mas não declara suas verdadeiras intenções. A reportagem da revista não faz questão de esconder que as ideologias perigosas para o aluno se localizam à esquerda no espectro da política.

Como fica claro na justificação do programa Escola sem Partido, bem como nas suas replicações pelas casas legislativas Brasil afora, (ressaltando) o programa não se fundamenta em estudos, pesquisas e teorias sobre o tema, mas, sim, em fato notório. Do ponto de vista jurídico, um fato notório dispensa provas uma vez que se trata de algo de conhecimento geral (SANTOS, 2001: 98).

Antes de discorrer sobre a questão "fato notório", cabe ressaltar, uma vez, que o programa acabou sendo replicado em diversas casas legislativas do 
país, achamos por bem, a certa altura da pesquisa, fazer referência a apenas a um deles, a saber, o Projeto de Lei no Senado n 193, de 2016. Isto posto, segue os argumentos que buscam justificar a necessidade do programa:

É fato notório que professores e autores de materiais didáticos vêm se utilizando de suas aulas e de suas obras para tentar obter a adesão dos estudantes à determinadas correntes políticas e ideológicas para fazer com que eles adotem padrões de julgamento e de conduta moral - especialmente moral sexual - incompatíveis com os que lhes são ensinados por seus pais ou responsáveis ${ }^{15}$.

Em função disso, exige-se que o professor, "ao tratar de questões políticas, socioculturais e econômicas, apresentará aos alunos, de forma justa, as principais versões, teorias, opiniões e perspectivas concorrentes a respeito" ${ }^{\text {.16 }}$.

Consta ainda no referido projeto que os estabelecimentos de ensino em nível básico "[...] deverão apresentar e entregar aos pais ou responsáveis pelos estudantes, material informativo que possibilite o pleno conhecimento dos temas ministrados e dos enfoques adotados"17. Diante disso, suspeitamos que instrumentos essenciais ao planejamento de trabalho docente, como planos de ensino e de aula, devam ser submetidos com antecedência à apreciação de pais e, ou, responsáveis. Estes exerceriam o papel de fiscalizadores, possivelmente com poder de liberação e veto sobre objetos de estudos em sala de aula.

Faz-se ainda necessário destacar que, no que tange as instituições de educação básicas, o programa propõe que seja afixado

[.... Nas salas de aula ${ }^{18}$ e nas salas dos professores cartazes com o conteúdo previsto no anexo desta Lei, com, no mínimo, 90 centímetros de altura por 70 centímetros de largura, e fonte com tamanho compatível com as dimensões $\operatorname{adotadas}^{19}$.

\footnotetext{
${ }^{15}$ Projeto de Lei 193, 2016, justificação.

${ }^{16}$ Projeto de Lei 193, 2016, Art. $5^{\circ}$, inciso IV.

${ }^{17}$ Projeto de Lei 193, 2016, Art. 4º parágrafo único.

${ }^{18}$ Refere-se ao Ensino Médio. Para o Ensino Fundamental a proposta diz respeito apenas as salas dos professores.

${ }^{19}$ Projeto de Lei 193, 2016, Art. $3^{\circ}$.
} 
Prevê-se também a implantação de "[...] um canal de comunicação destinado ao recebimento de reclamações relacionadas ao descumprimento desta Lei, assegurado o anonimato" ${ }^{20}$.

Diante de propostas como essas, Gadotti chama a atenção para o que denomina cultura da delação. O professor seria duplamente vigiado; de fora, pelos pais ou responsáveis e de dentro do ambiente escolar pelos discentes. Em face disso, argumenta,

O objetivo desse movimento é silenciar vozes, criminalizando o trabalho docente; é perseguir, demitir e até prender docentes que defendem uma visão de mundo contrária ao status quo e colocar a educação a serviço do mercado (GADOTTI, 2016: 153).

Embora o referido Projeto de Lei mencione que a neutralidade se dê também no campo religioso, a questão parece ser essencialmente política. E, ao que parece, especialmente no sentido de evitar temas espinhosos relacionados ao sistema econômico vigente e às doutrinas políticas adotadas pelas classes que detém o poder econômico no país.

Cabe ainda destacar o posicionamento de Leandro Karnal. Para o historiador, o Escola sem Partido

É uma asneira sem tamanho. É bobagem conservadora. É coisa de gente que não é formada na área, e que decide ter uma ideia absurda, que é substituir o que eles imaginam que seja uma ideologia em sala de aula por outra ideologia, que é uma ideologia conservadora. [...] Não existe escola sem ideologia. Seria muito bom que um professor não impusesse apenas uma ideologia, que abrisse caminho sempre para o debate. Mas é uma crença, em primeiro lugar, fantasiosa de uma direita delirante e absurdamente estúpida de que a escola forme a cabeça das pessoas e que esses jovens sejam líderes sindicais ${ }^{21}$.

Aparentemente, o Escola sem Partido tem pouco a ver com a educação em si. Nesse sentido, Fonseca (2016: 03) é incisivo: “o grande problema da educação no Brasil não é que os jovens leiam muito Marx na escola, é que saiam da escola sem saber ler". Se por um lado falta prova material para

\footnotetext{
${ }^{20}$ Projeto de Lei 193, 2018, Art. $8^{\circ}$.

${ }^{21}$ Disponível em: <https://tvcultura.com.br/videos/54607_roda-viva-leandro-karnal-04-07-

2016.html>. Acessado em 20/03/2017.
} 
comprovar que há doutrinação nas escolas, por outro, sobra dados e pesquisas apontando que a educação brasileira tem baixa qualidade. Não parece restar dúvidas, "O Movimento fundado por Nagib assume o nome Escola sem partido numa visível tentativa de sensibilizar a sociedade ao reduzir a micropolítica que atravessa a sala de aula à macropolítica partidária" (SARAIVA; VARGAS, 2017: 69). Não nos deixemos enganar, o programa não é neutro e nem está preocupado com a educação em si mesma.

\section{Um campo de disputas políticas}

Conforme o projeto de lei que estamos discutindo, “[...] professores e autores de materiais didáticos vêm se utilizando de suas aulas e de suas obras para tentar obter a adesão dos estudantes à determinadas correntes políticas e ideológicas [...]",22. A expressão "determinada correntes" nos remete a ideia de que os defensores do programa e o proponente do projeto partem do pressuposto de que o ensino básico não está isento de ideologias e que, portanto, é preciso neutralizá-las.

Louis Althusser (1918-1990), em Ideologias e Aparelhos Ideológicos do $E s t a d o^{23}$, nos ajuda a refletir e compreender melhor a questão. Ao que parece, a escola é um campo de disputa política. Se não, por que um grupo de pessoas, filiadas ou não a partidos políticos que representam determinadas ideologias e setores políticos estariam ocupando seu tempo debatendo projetos como o Escola sem Partido?

Conforme indica Malta, o educando em idade própria, na educação básica corresponde a parte mais fraca e vulnerável na relação de aprendizagem $^{24}$. E, em razão disso precisa ser protegido da doutrinação de algumas correntes políticas e ideológicas. Mas, perguntamos ao autor do Projeto de Lei 193, ao blindar o aluno do contato com certas ideologias, não se estaria interferindo na sua autonomia?

\footnotetext{
${ }^{22}$ Projeto de Lei 193, 2016, justificação.

${ }^{23}$ Escrito em 1969.

${ }^{24}$ Projeto de Lei 193, 2016, Art. $2^{\circ}$, inciso V.
} 
Quanto ao problema da vulnerabilidade mencionada anteriormente por Malta, é interessante analisar a citação que segue:

Desde a pré-primária, a escola toma a seu cargo todas as crianças de todas as classes sociais, e a partir da pré-primária, inculca-lhes durante anos, os anos em que a criança está 'vulnerável', entalada entre o aparelho de Estado familiar e o aparelho de Estado Escola [...] (ALTHUSSER, 1970: 64).

Ao que parece, o estudante é vulnerável a toda e qualquer ideia independente de seu conteúdo. Ou seja, o discente estaria vulnerável a qualquer ideologia. Mesmo quando esta não esteja explicitada em discursos, cores e símbolos. Nessa perspectiva, pressupomos que a inclusão do programa entre as Diretrizes e Bases da Educação Nacional teria uma dupla preocupação (não necessariamente nessa ordem): primeiro reivindicar para seus representados mais espaço na sala de aula para expor suas ideias; segundo, ameaçar, escantear (se possível, excluir) ideologias questionadoras do sistema político dominante no país ou contrárias ao que propõe os defensores do programa.

$\mathrm{Na}$ perspectiva de Althusser, a escola é um aparelho ideológico do Estado, ou seja, um tipo de instituição que não impõe os ideais de Estado pela violência, mas sim, por um conjunto de ideias que devem ser assimilados ao longo de um período de tempo. Ao analisar a referida obra do francês, somos levados a considerar que, na medida em que se avança na história ocidental, notamos que a escola, aos poucos, foi ganhando mais espaço na vida humana.

Nesse sentido, é interessante observar que mesmo discursando sobre a educação básica de seu país no final da década de 1960, o filósofo parece estar discorrendo sobre a realidade brasileira da segunda década do século 21: “[...] nenhum Aparelho Ideológico de Estado dispõe de tanto tempo da audiência obrigatória (e ainda por cima gratuita...) [...]” (ALTHUSSER, 1970: 66). A ideia poderia ser uma crítica ou um comentário ao inciso I, do artigo $4^{\circ}$, da Lei Federal $n^{\circ}$ 9.394, de 1996, que ordena: é dever do Estado garantir educação pública básica e gratuita às pessoas dos 4 aos 17 anos de idade.

O sujeito da educação passa quase toda a infância e a adolescência se escolarizando. Diante disso, Althusser nos leva a refletir: por que aqueles que detém o poder político e econômico estariam dispostos a aceitar quietos que se 
explore em sala de aula assuntos que serviria para estudantes questionarem os valores impostos pelas ideias dominantes?

Como afirmam Marx e Engels (2010: 57), “as ideias dominantes de uma época sempre foram as ideias da classe dominante". O que esperar das classes dominantes senão que desejem continuar a dominar?

Ao abordar questões políticas e econômicas em seu livro didático, Aranha e Arruda (2009: 337) afirmam: “[...] o capitalismo é um bom produtor de riqueza, mas um mau distribuidor dela". Nada demais e que não seja óbvio. Basta que o estudante faça uma breve observação da realidade empírica e então poderá chegar à conclusão similar. Notadamente há um distanciamento gritante entre pobres e ricos no Brasil. Entretanto, ao que parece, quando esse tipo de problema é apresentado por alguma autoridade intelectual, o Escola sem Partido tende a entender como tentativa de doutrinação.

É fato notório que há redes de escolas direcionadas à determinadas classes sociais (ou econômicas). Em geral, estudantes oriundos de famílias mais pobres são atendidos nas redes públicas de ensino. Embora o programa se dirija ao todo da educação, seu foco de observação parece estar centrado na educação básica pública.

O Brasil é um país em desenvolvimento e tem um notável histórico de dependência de recursos internacionais. Como coloca Santos e Andrioli, as regras são ditadas pelos donos dos recursos, não pelos que os recebem. Nesse sentido, afirmam:

Nesse quadro, as políticas educacionais são projetadas e implantadas segundo as exigências da produção e do mercado, com o predomínio dos interesses dos países ricos, isto é, daqueles que dominam a economia. O exemplo mais nítido disso na educação são as políticas dos órgãos internacionais, como o Fundo Monetário Internacional e o Banco Mundial. O discurso destes remete para a qualidade total na educação, onde os investimentos e benefícios são projetados e calculados da mesma forma como se procede em uma empresa ${ }^{25}$.

\footnotetext{
${ }^{25}$ Disponível em: http://rieoei.org/edu_des2.htm. Acessado em 12/10/2017.
} 
Diante disso, parece haver muitos objetivos escondidos nas entrelinhas do Escola sem Partido. E, todos eles parece apontar para a mesma direção: manter a(s) classe(s) dominada(s) refém da(s) classe(s) dominante(s) com um sistema político e governos que, como afirma Dussel (2007: 09), há mais de 500 anos vem cumprindo os interesses de metrópoles de plantão (hoje, os EUA). Por isso, os discursos em torno da defesa do programa tendem a demonizar pensadores, professores, escritores de materiais didáticos e quaisquer pessoas que se contrapõem às suas ideias. Os objetos mais notáveis dessa demonização são os brasileiros Frei Beto (1944) e Paulo Freire (1921-1997), em geral, tratados com certo desprezo, como no caso da matéria de Veja, anteriormente citada.

Um programa de controle na sala de aula

Conforme o Escola sem Partido, a lei se estenderia aos materiais didáticos e paradidáticos ${ }^{26}$. Diante disso, uma dúvida: o projeto não estaria forçando a criação de uma espécie de index imaginário de conteúdos proibidos? Façamos o esforço de imaginar como seria a recepção de algumas obras e de alguns conteúdos específicos "indexados".

Entre os livros publicados pelo (a) Laerte Coutinho, consta um cujo título por si só já chamaria a atenção do programa: Deus Segundo Laerte (com prefácio de Frei Beto anunciado na capa). Trata-se de uma obra de história em quadrinhos e a deidade em questão que aparece nas tirinhas foge à concepção de Deus segundo o cristianismo, como se pode constatar na passagem que segue:

Imagem 1 - A criação

\footnotetext{
${ }^{26}$ Projeto de Lei 193 , art. $9^{\circ}$, inciso II.
} 


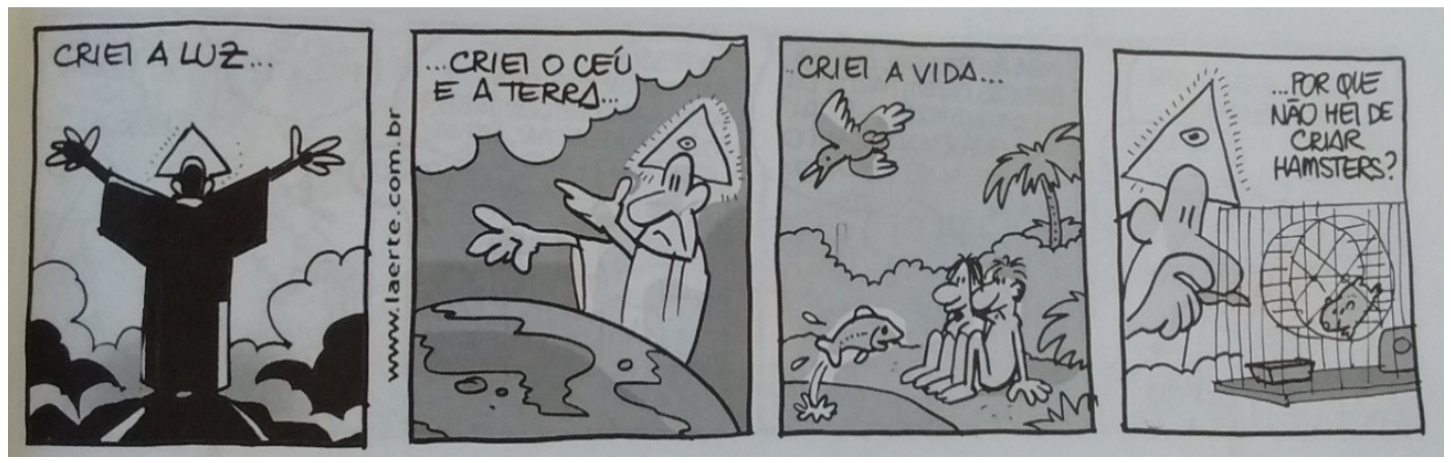

Fonte: COUTINHO, 2005: 09.

Livros como este não seriam questionáveis em relação a neutralidade religiosa? Em princípio, não. Pois trata-se de uma obra em estilo humorístico que apresenta Deus numa versão caricatural. Porém, na perspectiva do programa a história em quadrinho, ao que parece, poderia soar ofensiva, estimulante à descrença na concepção cristã de Deus. De antemão, não é possível saber exatamente qual seria a reação dos defensores do programa caso este fosse transformado em Lei Federal. Porém, pode-se pressupor que obras como a de Laerte seriam facilmente isoladas dos estudantes.

Mas, e quando se trata de livros didáticos, como no caso de obras sugeridas pelo Programa Nacional do Livro Didático (PNLD) e disponibilizadas às escolas públicas?

Ao analisar os livros didáticos sugeridos pelo referido programa para o triênio 2015-2017 para a disciplina de Filosofia ${ }^{27}$, nota-se que, se submetido ao crivo do programa, várias passagens poderiam ser objetos de veto. Entretanto, por se tratarem de temas clássicos, poderiam ser extirpados de suas páginas por exigência de programa? Excluir temas debatidos dos grandes pensadores da humanidade por um capricho ideológico seria uma perda irreparável.

Segue alguns exemplos

O filósofo alemão Feuerbach, [...] investigou como se formam as religiões e como os seres humanos sentem

\footnotetext{
${ }^{27}$ As obras são: Iniciação à Filosofia, de Marilena Chauí; Filosofando: Introdução à Filosofia, de Maria Lúcia de Arruda Aranha e Maria Helena Martins Pires; Filosofia: Experiência do Pensamento, de Sílvio Gallo; Fundamentos de Filosofia, de Gilberto Cotrim e Mirna Fernandes e Filosofia: Por uma Inteligência da Complexidade, de Celito Meier.
} 
necessidade de oferecer uma explicação para a origem e a finalidade do mundo. Ao buscar essa explicação, Feuerbach constatou que os humanos projetam para fora de si um ser superior dotado de qualidades que julgam ser as melhores: inteligência, vontade livre, bondade, justiça, beleza. Porém, elas aparecem nesse ser supremo como superlativas: este ser é onisciente e onipresente [...]. Pouco a pouco, os humanos se esquecem de que criaram esse ser e passam a acreditar no inverso [...]. Passam a adorá-lo, prestar-lhe culto, temê-lo. Para Feuerbach, quando os homens não se reconhecem num outro que eles mesmos criaram, eles se alienam (CHAUÍ, 2013: 167).

Em princípio, mostrar posicionamentos como este, que se contrapõe a visão cristã sobre Deus, pode ser instigante para o aluno, no sentido de perceber que a questão deus é filosoficamente problemática. O intuito, nesse e em muitos outros casos, é provocar a reflexão, a inquietação, o debate. Entretanto, é notório $^{28}$ que o Brasil é um país cuja religião dominante é o cristianismo e, muitas vezes e situações, na perspectiva de muitos de seus adeptos, a visão teológica sobre a realidade se sobrepõe ao saber científico, filosófico, sociológico. Diante disso, qual seria a reação de um aluno convicto de sua fé religiosa e pró Escola sem Partido, ao ser provocado a debater a questão "Deus" colocada em Feuerbach?

Outro tema presente em todos os livros didáticos é a liberdade. Em geral, ao tratar da subárea Ética ou Filosofia Moral, apresenta-se diversas concepções do conceito. Entre essas concepções é notável a formulação de Jean-Paul Sartre (1905-1980). Transcrevendo o conceito sartreano contido em O Existencialismo é um Humanismo, Gallo (2013: 131) traz a seguinte passagem, “[...] o ser humano é livre, e a liberdade consiste no ato da escolha”. A princípio não há nada que poderia causar polêmicas e suspeitas de proselitismo. Entretanto, ao se aprofundar na explicação do conceito pode-se incorrer em "problemas". Em Sartre, Deus é desnecessário. O homem é liberdade. Caso Deus existisse, o homem não seria livre. Trata-se do

\footnotetext{
${ }^{28}$ Nesse caso, a aplicação da noção de fato notório faz todo o sentido.
} 
existencialismo ateu ${ }^{29}$ apresentado (com mais ou com menos ênfase) pelos autores de livros didáticos, como pode ser constatado em Chauí (2013, cap. 28), Aranha (2009, cap. 21), Gallo (2013, unid. 3, cap. 1), Cotrim (2013, cap. 16).

Se atentarmos para a concepção de moral que Malta tem em mente nas propostas do programa descritas no projeto de lei que ele assina, teremos motivos suficientes para desconfiar que temas como, Deus em Feuerbach e liberdade em Sartre não seriam bem vistos. No entendimento do proponente, "[...] a moral é inseparável da religião" ${ }^{30}$. Mas é preciso lembra, a moral ${ }^{31}$ cristã não é a única possível.

Sartre, além de um importante pensador da tradição filosófica, é fundamental para se refletir acerca da existência humana, especialmente em relação ao ocidente do pós-guerra(s). Mas, será que diante de ameaças do programa, uma vez que esse se transformasse em Lei Federal, os docentes da disciplina de Filosofia o tratariam com a devida profundidade? Dependendo das circunstâncias e do peso da penalidade que fosse aplicada, provavelmente os professores tenderiam a trabalhar com temas que não "ofendessem" o programa.

Outro autor que correria o risco de ter seu pensamento banido ou discutido em nível superficial é Karl Marx (1818-1883). O marxismo é imprescindível para se discutir criticamente o modo de produção vigente no Brasil. Marx, talvez, seja o teórico mais visado pelo Escola sem Partido, pois suas ideias fundamentam boa parte das discussões e posicionamentos à esquerda em termos políticos. Nesse sentido, todas as cinco obras sugeridas pelo PNLD (edição 2015-2017) abordam abundantemente o marxismo.

\footnotetext{
${ }^{29}$ Faz se necessário acrescentar esse qualitativo para distinguir Sartre, Martin Heidegger (18891976) e Albert Camus (1913-1960) de existencialistas cristãos, como Karl Jaspers (1883-1969) e Gabriel Marcel (1889-1973).

${ }^{30}$ Projeto de Lei 193, 2016, justificação.

${ }^{31}$ A moral "em um sentido amplo, sinônimo de ética como teoria dos valores que regem a ação ou conduta humana, tendo um caráter normativo ou prescritivo. Em um sentido mais estrito, a moral diz respeito aos costumes, valores e normas de conduta específicos de urna sociedade ou cultura, enquanto que a ética considera a ação humana do seu ponto de vista valorativo e normativo, em une sentido mais genérico e abstrato (JAPIASSÚ, 2006: 193).
} 
Não foi objeto de pesquisa analisar amplamente os conteúdos dos livros didáticos e apontar itens que poderiam se contrapor as ideias do Escola sem Partido. Diante disso, bastam os exemplos supracitados.

Embora a neutralidade se estenda para outros campos de discussão, o foco do "programa" está voltado essencialmente para questões de natureza política e ideológica, sendo que um dos objetivos implícitos é o controle sobre o trabalho dos docentes e produtores de material didático.

\section{Considerações finais}

Existe uma quantidade enorme de leis em vigor no Brasil. Boa parte delas é como se não existissem. Muitas leis simplesmente são ignoradas pelos cidadãos. Um exemplo: a Lei Federal n 13.006. Aprovada em 2014, acrescenta à LDB o seguinte parágrafo:

A exibição de filmes de produção nacional constituirá componente curricular complementar integrado à proposta pedagógica da escola, sendo a sua exibição obrigatória por, no mínimo, 2 (duas) horas mensais ${ }^{32}$.

Na prática a norma significa apenas mais uma lei que, como se diz na linguagem popular, "não pegou", pois é pouco provável que as escolas a cumpram efetivamente. Conforme o jornal Brasil de Fato, estima-se que haja mais de 60 projetos de lei relacionados ao programa tramitando em todo o país $^{33}$. O Escola sem Partido já foi aprovado em diversos municípios - por exemplo, em Picuí (PB), em Jundiaí (SP), em Campo Grande (MS), em Criciúma (SC) e em Santa Cruz do Monte Castelo (PR). Em nível estadual, os defensores do projeto conseguiram até aqui ${ }^{34}$ apenas uma aprovação na Assembleia Legislativa do Estado de Alagoas. O Projeto de Lei no Senado ${ }^{\circ}$ 193, de 2016, principal objeto em torno do qual girou toda a nossa discussão,

\footnotetext{
${ }^{32}$ Brasil, Lei $9.394,1996$, Art. $26^{\circ}$, parágrafo 8.

${ }^{33}$ Disponível em: ttps://www.brasildefato.com.br/2017/09/29/escola-sem-partido-ja-virou-leiem-pelo-menos-quatro-cidades-brasileiras. Acessado em 15/10/2017.

3413 de novembro de 2017.
} 
foi retirado em definitivo pelo seu autor em 21 de novembro de 2017 e destinado ao arquivo do Congresso Nacional.

\section{Referências}

ALTHUSSER, L. Ideologia e Aparelhos Ideológicos do Estado. Lisboa: Editorial Presença, 1970.

Escola Sem Partido já virou lei em pelo menos quatro cidades brasileiras. Brasil de Fato. São Paulo, 29 de set. de 2019. Disponível em: $<$ https://www.brasildefato.com.br/2017/09/29/escola-sem-partido-ja-virou-leiem-pelo-menos-quatro-cidades-brasileiras/>. Acesso em: 15 de out. de 2017.

ARANHA, M. L. de A.; MARTINS, M. H. P. Filosofando: Introdução à Filosofia. $4^{\circ}$ ed. São Paulo: Moderna, 2009.

BRASIL. Lei Federal $\mathrm{n}^{\circ} 9.394$ de 1996. Disponível em: $<$ http://www.planalto.gov.br/ccivil_03/leis/L9394.htm>. Acesso em 20 de jul. de 2017.

BRASIL. Projeto de Lei no Senado $\mathrm{n}^{\circ} 193$ de 2016. Disponível em: $<$ https://www25.senado.leg.br/web/atividade/materias/-/materia/125666>.

Acesso em: 09 de jan. de 2017.

CHAUÍ, M. Iniciação à Filosofia: Ensino Médio. $2^{\circ}$ ed. São Paulo: Ática, 2013.

COTRIM, G.; FERNANDES, M. Fundamentos de Filosofia. $2^{\circ}$ ed. São Paulo: Saraiva, 2013.

COUTINHO, L. Deus Segundo Laerte. São Paulo: Olho D’Água, 2005.

DUSSEL, H. 20 Teses de Política. Tradução de Rodrigo Rodrigues. São Paulo: Expressão Popular, 2007.

ESCOLA SEM PARTIDO. Disponível em: $<$ https://www.facebook.com/escolasempartidooficial/ $>$. Acesso em: $10 \mathrm{de} \mathrm{dez.}$ de 2016.

ESCOLA SEM PARTIDO. Disponível em: $<$ http://www.programaescolasempartido.org $>$. Acesso em: 10 de dez. de 2016.

FONSECA, J. P. da. Escola sem Partido não resolve o problema e torna o professor refém. Folha de São Paulo, São Paulo, 31/07/2014. Ilustríssima. 
FRIGOTTO, G. A gênese das teses do Escola sem Partido: esfinge e ovo da serpente que ameaçam a sociedade e a educação. In: FRIGOTTO, G. Escola "sem" Partido: Esfinge que Ameaça a Educação e a Sociedade Brasileira. Rio de Janeiro: UERJ, LPP, 2017, p. 17-34.

GALLO, S. Filosofia: Experiência do Pensamento. São Paulo: Scipione, 2013.

GADOTTI, M. A escola cidadã frente ao "Escola sem Partido". In.: SOUZA, A. L. S. et. al. A Ideologia do Movimento Escola sem Partido: 20 Autores Desmontam o Discurso. São Paulo: Ação Educativa, 2016, p.148-165.

Guia de Livros Didáticos: PNLD 2015. Filosofia: Ensino Médio. Brasília: Ministério da Educação, Secretaria de Educação Básica, 2014.

JAPIASSÚ, H..; MARCONDES, D. Dicionário Básico de Filosofia. $4^{\circ}$ ed. Rio de Janeiro: Zahar, 2006.

KATZ, E. P.; MUTZ, A. S. da C. Escola sem partido - produção de sentidos e disputas em torno do papel da escola pública no Brasil. ETD: Educação Temática Digital, Campinas, v. 19, n. 1, p. 184-205, 2017.

LEANDRO KARNAL. Roda Viva. São Paulo: TV Cultura, 04 de jul. de 2016. Entrevista. Disponível em: <https://tvcultura.com.br/videos/54607_roda-vivaleandro-karnal-04-07-2016.html>. Acesso em: 20 de mai. De 2017.

MARX, K.; ENGELS, F. Manifesto Comunista. Tradução de Álvaro Pina e Ivana Jinkings. São Paulo: Boi Tempo, 2010.

MANAS, C. Nada mais ideológico que "Escola sem Partido". In.: SOUZA, A. L. S. et. al. A Ideologia do Movimento Escola sem Partido: 20 Autores Desmontam o Discurso. São Paulo: Ação Educativa, 2016, p.15-21.

MEIER, C. Filosofia: Por uma Inteligência da Complexidade. Belo Horizonte: Pax Editora, 2010.

RATIER, R. 14 perguntas e respostas sobre o "Escola sem Partido". In.: SOUZA, A. L. S. et. al. A Ideologia do Movimento Escola sem Partido: 20 Autores Desmontam o Discurso. São Paulo: Ação Educativa, 2016, p.29-41.

Você sabe o que estão ensinando a ele? Veja, n³3, ano 33, edição 2.074. São Paulo: Abril Cultural, 2008.

SANTOS, W. dos. Dicionário Jurídico Brasileiro. Belo Horizonte, Del Rei, 2001. 
SANTOS, R; ANDRIOLI, A. I. Educação, globalização e neoliberalismo: o debate precisa continuar. Revista Iberoamericana de Educación, Espanha, v. 35, p. 68-84, 2017.

SARAIVA, K.; VARGAS, J. R. de. Os perigos da Escola sem Partido. Teias, Rio de Janeiro, v. 18, n. 51, p. 68-84, 2017.

Recebido em: 27 de julho de 2019 Aceito em: 05 de dezembro de 2019 